\title{
"ESTÔMAGO”, O FILME: UMA ANÁLISE PROJETANDO A COMIDA ENQUANTO PRATO PRINCIPAL PARA O CINEMA
}

\author{
Uliana Kuczynski \\ Orientação: Dennison de Oliveira
}

PALAVRAS-CHAVE: cinema brasileiro, comida, filme "Estômago".

A pesquisa que será aqui sintetizada tem como objetivo mostrar a relação entre a produção cinematográfica e a comida, através do longa-metragem Estômago, do diretor curitibano Marcos Jorge. O filme foi eleito por ser uma produção paranaense e por ter como fio condutor da narrativa a temática da comida, tão explorada em obras internacionais como Sem Reservas, O Jantar, Tampopo ou Uma Receita para a Máfia. O lançamento do filme foi em 2007, e por esse motivo serão contemplados alguns aspectos atuais da cinematografia nacional. Aspectos esses que se inserem em um recorte do cinema brasileiro denominado "Retomada", pouco explorado por historiadores.

Já que estamos tratando do cinema enquanto fonte histórica, vale frisar alguns fatores que sustentam a análise. São eles: a interpretação da estética e da linguagem cinematográfica (entendida como a combinação dos movimentos e enquadramentos da câmera com outros elementos como som, fotografia, iluminação, cenário, etc.) oferecidas pelo próprio filme e que lhe conferem sentido; a relação do filme com a sociedade que o produz e consome abarcando as circunstâncias de produção, distribuição, exibição e recepção -, entendendo-o como agente e como produto da História; e por fim, pensá-lo como uma expressão do imaginário do homem. Pois o filme não é meramente uma imagem ilustrativa, mas uma construção humana, uma representação ${ }^{353}$, e é desta forma que

353 Essa metodologia tem base nas obras de Marc Ferro, analisadas por MORETTIN, Eduardo V. O Cinema a como fonte histórica na obra de Marc Ferro. 
trataremos a pesquisa, visando desenvolver uma contextualização contundente para assim degustarmos o conteúdo fílmico propriamente dito.

Situando, então, o cinema da "Retomada", podemos inseri-lo no período em que o Estado reafirma sua ligação com a sétima arte, a qual fora interrompida devido à extinção da Embrafilme (1990), deixando os cineastas desprovidos de um órgão responsável pela indústria do cinema. Depois de uma reconfiguração na administração estatal, as produções contam com a participação indireta do Estado, desde 1993, através de incentivo fiscal pela Lei do Audiovisual, ancorada à Lei Rouanet. A partir de 2001 a Agência Nacional de Cinema (Ancine) se responsabiliza pelo fomento e regulação da atividade cinematográfica. Mas é a partir daquela lei de incentivo que a produção começa a ser reerguida, restabelecida, "Retomada".

No caso de Estômago, ele é produto de uma co-produção recente, realizada em parceria com a Itália. Filmado em território nacional (em Curitiba, especificamente, e com algumas cenas em São Paulo) e finalizado com a técnica italiana, o primeiro longa-metragem de Marcos Jorge expressa essa característica que tem rendido bons resultados ao mercado cinematográfico. As co-produções viabilizam os projetos e garantem uma técnica mais aprimorada, possibilitando, inclusive, uma circulação mais global.

No entanto, o diagnóstico desta indústria nacional ainda se revela incipiente nos setores de distribuição e exibição (pilares essenciais para o circuito, além da produção) ${ }^{354}$, e ainda, se formos pensar no âmbito total da cadeia produtiva, que ultrapassa as salas de cinema e abrange ainda o home-vídeo, a TV paga e a TV aberta, também constatamos uma deficiência no alcance do público geral

História: Questões \& Debates. Curitiba, nº 38, Editora UFPR, 2003; KORNIS, Mônica. História e Cinema: um debate metodológico. Estudos Históricos, Rio de Janeiro, vol 5, n 10, 1992.

${ }^{354}$ LEITE, Sidney Ferreira. Cinema brasileiro: das origens à retomada. São Paulo: Editora Fundação Perseu Abramo, 2005. 
para o cinema brasileiro. ${ }^{355}$ Já na produção regional, o Paraná se mostra com uma ínfima parcela de participação, devido à acentuada concentração no Rio de Janeiro e em São Paulo, e em termos de identidade volta-se para o curta-metragem e o documentário.

Porém o cinema não deve ser entendido somente pelo viés institucional, industrial e mercadológico. Jacques Aumont lembra-nos dos significados estéticos (por ser uma obra de arte) incutidos no filme ${ }^{356}$, os quais, para o caso desta pesquisa, favorecerão a configuração do sentido do filme em questão.

Quanto à temática, a produção fílmica do período aqui recortado caracteriza-se pela variedade e pelo pragmatismo, distanciando-se dos compromissos ideológicos típicos do Cinema Novo e aproximando-se de uma linguagem técnica internacional. Desde a comédia romântica à violência, o Brasil explora temas diversos, não necessariamente e especificamente nacionais. Estômago insinua alguns aspectos que reconhecemos enquanto brasileiros, como o êxodo rural e a figura do nordestino no personagem principal Raimundo Nonato. A lotação do sistema carcerário (um dos cenários de filme) também é mostrada. Mas isso é secundário no conjunto da obra, não há uma problematização centrada nesses aspectos, evidenciando que a questão do cozinheiro é que ganha o papel principal.

A película não pertence à categoria dos chamados "filmes históricos", tampouco tem como foco principal as mazelas sociais brasileiras, que renderam alguns prêmios a outras produções nacionais. Trata-se de uma ficção cuja peculiaridade temática reside na sua trama central: a ascensão social de Raimundo Nonato através de seu recém-descoberto talento gastronômico.

355 CESÁRIO, Lia Bahia. O debate contemporâneo sobre as leis e políticas públicas do audiovisual no Brasil. Trabalho apresentado no VII Encontro dos Núcleos de Pesquisa em Comunicação - NP de Comunicação Audiovisual, 2007. ${ }^{356}$ AUMONT, Jacques. A Estética do filme. Campinas: Papirus, 1995, p. 17 
Descrito na sinopse do site oficial como "uma fábula nada infantil sobre poder, sexo e culinária”357, o filme narra a história de um retirante que chega na cidade grande sem perspectivas mas que, como foi dito, conquista, ao longo da trama, posições de prestígio por conta de suas habilidades culinárias, que vão desde a cozinha de boteco à famosa culinária italiana. Essas habilidades lhe rendem um emprego e uma paixão, servindo de base para suas relações sociais. Parte do filme se passa na cela da penitenciária que detém Nonato - a narrativa não-linear intercala presente (cadeia) e passado (boteco/restaurante) -, e lá, também, ele conquista o respeito e uma posição de destaque entre os presos por transformar (quase que milagrosamente) aquilo que recebiam como alimento em verdadeiros quitutes. Nesse sentido o filme nos traz dois temas universais: a comida e o poder.

Como neste caso comida é poder, e é o cerne do filme, podemos colocá-lo no rol de obras que tem a comida como protagonista. ${ }^{358}$ São filmes como A Festa de Babette ou $O$ cozinheiro, o ladrão, sua mulher e o amante. Obras que a partir de meados da década de oitenta transitam em torno do ambiente de cozinhar (tanto a cozinha como o restaurante), da figura do cozinheiro ou do ato de sentar-se à mesa, e que agora contam com o representante brasileiro neste mesmo rol. Note-se que aqui estamos entendendo a comida não somente pelo seu caráter nutricional, mas também inserida em uma cultura, cercada de sociabilidades e imbricadas na História. Ou seja: "alimentar-se é um ato nutricional, comer é um ato social, pois constitui atitudes, ligadas aos usos, costumes, protocolos, condutas e situações" 359 .

\footnotetext{
${ }^{357}$ www.estomagoofilme.com.br

358 DUCROT, Víctor Ego. Los Sabores del Cine. Buenos Aires: Grupo Editorial Norma, 2002.

359 SANTOS, Carlos Roberto Antunes dos. A Alimentação e o seu lugar na História: os tempos da memória gustativa. História: Questões \& Debates. Curitiba, n ${ }^{\circ}$ 40, p.11 - 31, Editora UFPR, 2005. p 12.
} 
Tema tão discutido atualmente, seja nas revistas de milagrosas receitas dietéticas ou nos livros de gastronomia, ou ainda nos debates por uma "alimentação saudável”, a comida ganha destaque não só no cotidiano, mas perpassa as obras cinematográficas, tornando-se problema para a própria historiografia. O culto ao corpo, a figura do chef de cozinha cada vez mais aparente na mídia, e as discussões em torno dos fast-food e da ingestão da carne, sinalizam tal temática como polêmica, ou até como uma "espetacularização" da comida ${ }^{360}$.

Algo que traduz essa "espetacularização" da sociedade para a película é a utilização do primeiro plano na maioria das cenas em que Raimundo Nonato cozinha (enquadramento que limita o campo de visão àquilo que o personagem está preparando - escolha do diretor para transmitir suas intenções ao espectador). Nessas cenas existe bastante iluminação e elas são fixadas por um tempo suficiente para chamar atenção e incomodar o paladar daquele que assiste (ora incitando o apetite, ora provocando reações de desgosto). Além disso, pelo roteiro, podemos perceber que é a parir da ênfase no preparo ou na degustação das iguarias de Nonato que os pontos de virada, as ações principais da narrativa se desencadeiam. Um exemplo é o fato do cozinheiro ter conquistado Íria (personagem da atriz curitibana Fabíula Nascimento) pelo sabor das coxinhas por ele preparadas.

Neste momento, vale lembrarmo-nos da relação do autor com a obra, também um fator metodológico essencial. Ora, o diretor e a produtora do filme, Cláudia da Natividade, tiveram especialização e atuação profissionais na Itália, que, ao lado da França constituem o emblema da gastronomia ocidental. Isso ajuda-nos a entender a opção pelo tema, somado ainda à declaração do próprio Marcos Jorge que se diz um admirador da culinária daquele país. Ele diz gostar de tratar temas humanos e justifica o tema do filme por não haver nada tão humano quanto cozinhar! ${ }^{361}$

\footnotetext{
360 SANT’ANNA, Denise Bernuzzi. Transformações das intolerâncias alimentares em São Paulo, 1850 - 1920. História: Questões \& Debates. Curitiba, nº 40, p 8193, Editora UFPR, 2005.

${ }^{361}$ www.estomagoofilme.com.br
} 
Estômago conquistou, até o presente momento, quatro prêmios nacionais (no Festival do Rio - 2007, onde foi lançado), e oito internacionais (quatro deles foi no Festival Valladolid, na Espanha) com destaque para o ator João Miguel, para a direção e para o filme em si. Já foi vendido para onze países e estampado na mídia impressa e virtual, inclusive internacionalmente.

Podemos constatar, então, que a universalidade do tema, bem como a tática de co-produção foram elementos que garantiram uma boa recepção desse longa-metragem, elevando a expressividade do cinema paranaense e incluindo-o no que pode ser entendido como um "gênero da comida". Já com relação à historiografia, essa obra permitiu um trabalho que abrangeu desde as condições da indústria e do mercado cinematográfico contemporâneo, às representações que o filme traduz e introduz na sociedade. Além disso, mostrou que o cinema se constitui num prato cheio enquanto fonte histórica. 